\title{
Verification of Computer Simulation Results of Bus Body Section Rollover
}

\author{
Rogov Petr Sergeevich and Orlov Lev Nikolaevich \\ Transport Systems Institute, Nizhny Novgorod State Technical University n.a. R. E. Alekseev, Nizhny Novgorod 603950, Russian \\ Federation
}

\begin{abstract}
The main objective of this study is the search for methods of verification of bus rollover finite element simulation which can replace a full-scale verification rollover test using single bus section. An overview of the main verification methods of the computer simulation results of bus rollover is provided in the article. A bus section rollover test is conducted. A comparison between calculation and experiment results is performed. Features of bus section motion, which affect the construction deformation value, are analyzed on the basis of received good convergence between calculation and test results. The mathematical model of planar motion of the bus section until impact with ditch surface is given. This model can be used to verify values of the center of gravity velocities and accelerations of the bus section, obtained as a result of an FE (finite element) simulation.
\end{abstract}

Key words: ECE R66, finite element modeling, passive safety, bus, light commercial vehicle.

\section{Introduction}

The official requirement, which regulates the structural strength of the bus body in rollover accident, is prescription of the UNECE (United Nations Economic Commission for Europe) Regulation 66. This regulation describes the rollover test conditions of the bus and evaluation criteria of the bus passive safety. The basic evaluation method is to conduct a full-scale rollover of the bus from a ledge of $0.8 \mathrm{~m}$ height. The scheme of the test is shown in Fig. 1. A vehicle on the platform is gradually tilted. When the COG (center of gravity) of the bus reaches the maximum height (Position 2), the bus begins to fall. The free fall continues until the first contact between the bus body construction and rigid ditch surface occurs, which corresponds to Position 3 of the COG of the bus.

The rules also provide equivalent methods of evaluation, namely quasi-static calculations and tests and computer simulation [1]. In the quasi-static test and

Corresponding author: Rogov Petr Sergeevich, post graduate, assistant lecturer, research fields: finite element analysis and passive safety of vehicles. E-mail: dr_verhovtcev@mail.ru. calculation, the rules prescribe the following impact energy value:

$$
E=0.75 \mathrm{Mg} h
$$

where, $M$ is the mass of bus, $g$ is the gravitational acceleration and $h$ is the vertical distance between Positions 2 and 3 of the COG of the bus (Fig. 1).

Computer simulation of bus rollover is currently performed using software based on the FEM (finite element method). In assessing the passive safety of bus bodies using FEM, great attention is paid to verification of the results. To obtain an adequate simulation result, the information about nonlinear characteristics of the materials used in the construction of the bus body is needed. An important factor determining a real character of the structure behavior during deformation process is a method of modeling connections (welding, glue and bolted connections) of elements of the body construction. Correct selection of the above mentioned parameters can be achieved by carrying out experiments on specimens of materials, structural elements as well as their connections [2, 3]. Fragments of the verification tests, which were carried out by Vashurin [4], are shown in Fig. 2. 


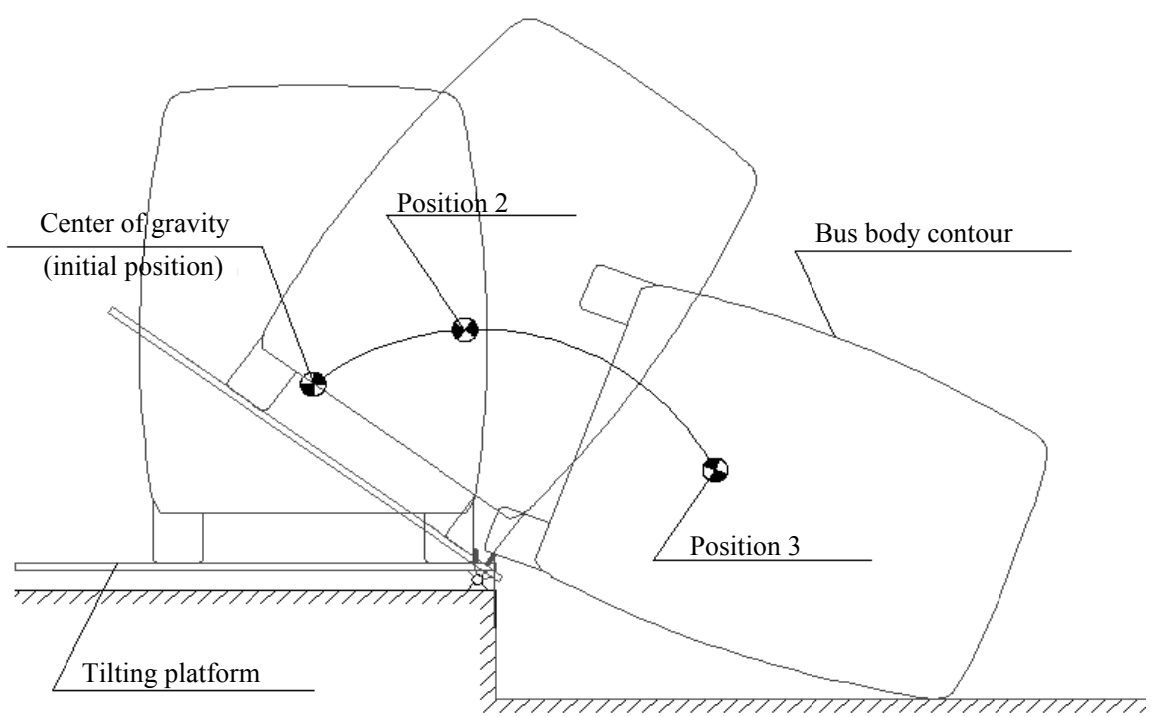

Fig. 1 Scheme of the bus rollover test according to ECE R66.
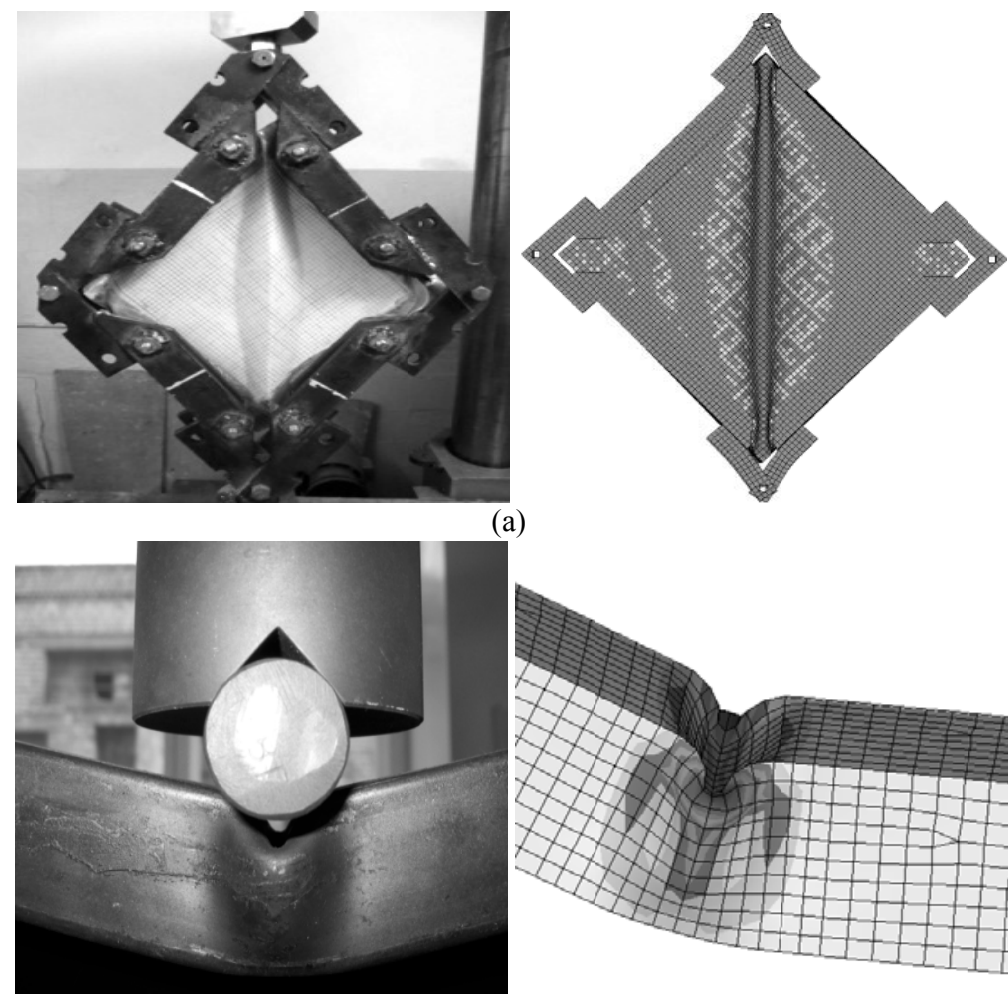

(a)

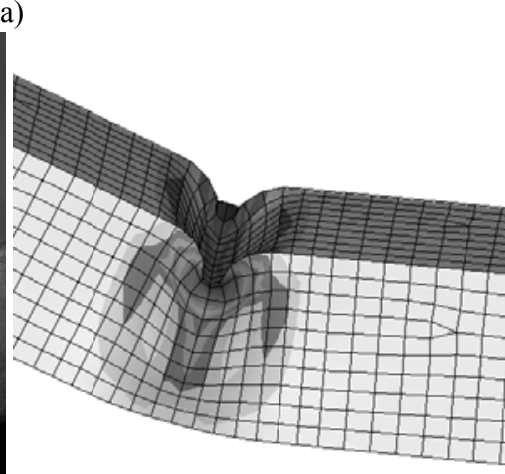

(b)

Fig. 2 Verification tests for assessing of an accuracy of the computer simulation results: (a) shear test of a sandwich panel; (b) three-point bending test of thin-walled tube.

Another way to check the accuracy of the computer simulation results is the analysis of a balance of calculated energy values. For explicit nonlinear numerical solver LS-Dyna, this balance looks as follows:

$$
\begin{aligned}
E_{\text {total }}=E_{\mathrm{kin}}+E_{\text {int }}+E_{\mathrm{sli}}+E_{\mathrm{hg}}+E_{\mathrm{damp}}+E_{\mathrm{rw}} \\
=E_{\mathrm{kin}}^{0}+E_{\text {int }}^{0}+W_{\mathrm{ext}}
\end{aligned}
$$

where, $E_{\text {total }}$ is the total energy, $E_{\text {kin }}$ is the kinetic energy, $E_{\text {int }}$ is the internal energy, $E_{\text {sli }}$ is the energy of contact (sliding), $E_{h g}$ is the hourglass energy, $E_{\text {damp }}$ is 
the damping energy and $E_{\mathrm{rw}}$ is the rigid wall energy. This sum must be balanced by the sum of initial kinetic energy $E_{\text {kin }}^{0}$, initial internal energy $E_{\text {int }}^{0}$, and external work from the applied loads $W_{\text {ext }}[5]$.

Both of these verification methods allow to choose an optimal size, shape, formulation of the finite element and optimal size of the iteration step. Thus, it is possible to evaluate an adequacy of behavior of an FEM at the time of impact with ditch surface and of subsequent deformations. However, it is important to assess a character of bus motion during a free fall, since it is possible to obtain the deviation in magnitude of the kinetic impact energy and components distribution of the model velocity. All of these can affect the result of modeling, even with good convergence obtained between calculation and experiment on structural elements specimens of the construction.

Assessment of the adequacy of the model parameters listed above, as well as the accuracy of the translational and angular velocities values of the model at the time of impact with ditch surface is possible by means of a natural experiment on a single section of the bus $[6,7]$.

Although the verification by this method is the most full-scale, we must not forget about the shortcomings of this experiment. The first disadvantage is the high cost. The second disadvantage is the necessity for an existing object of research, which makes impossible the conduction of verification during the bus design process before manufacturing of the first prototype. Therefore, the aim of this study is the analysis of bus rollover process, the determination of the most important parameters of bus motion, which can be specified using simplified experiments without a prototype and searching for equivalent methods of verification. Thus, the search for solutions that can help to replace a full-scale experiment conduction will be carried out in this article.

In order to understand what features of bus motion at rollover may affect the deformations and the impact energy changing, the comparison between FE (finite element) simulation and full-scale experiment on the example of a bus single section will be carried out below.

\section{Object of the Study}

The object of this study has contour and structural elements similar to corresponding parameters of the middle section of a typical bus, which is performed on the base of a light commercial vehicle. Before testing, the section was set on a pedestal, which simulated the vehicle chassis. Then the ballast was added in order to give the section mass properties (mass and COG location) similar to the bus body section. The ballast was joined to the section structural elements and the pedestal. The tilting platform with the section, pedestal and ballast is shown in Fig. 3.

\section{Description of the Finite Element Simulation}

The uniaxial tensile test of the specimens extracted from thin-walled tubes of the body section was conducted preliminarily. The "stress-strain" curve obtained for plastic deformation area (Fig. 4) was assigned to the material of the body section at the FEA (finite element analysis). FEA was conducted using

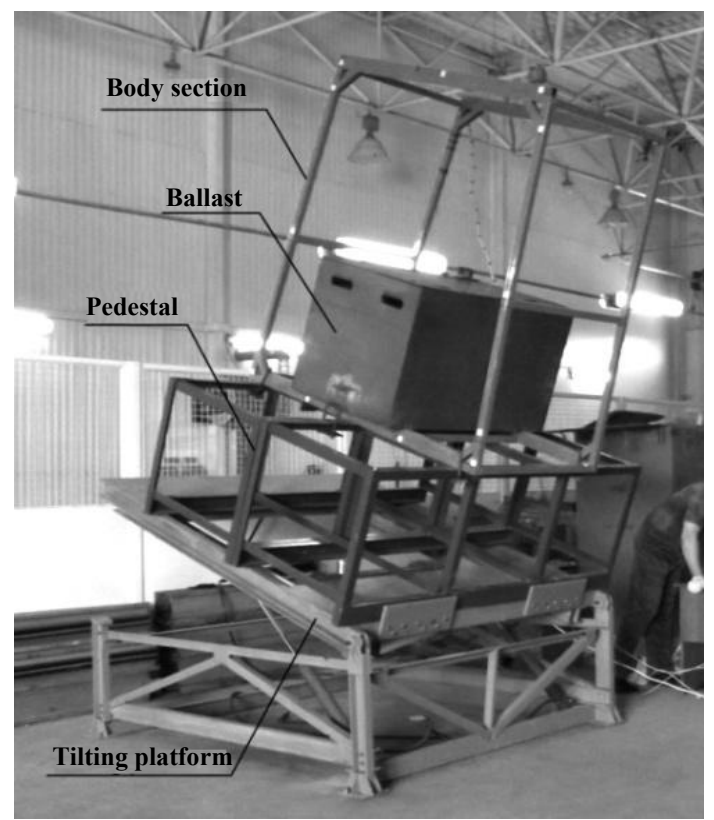

Fig. 3 The tilting platform together with the mounted section. 
LS-Dyna double precision solver. The simulation process started from the time moment, corresponding to the position of unstable equilibrium of the structure (Position 2 of the COG in Fig. 1). The acceleration of gravity was assigned to the FEM.

The section pedestal, tilting platform with shoulders and ditch surface were modeled by rigid bodies. The whole rollover process takes $2.2 \mathrm{~s}$. The body section's material with assigned plastic hardening curve was switched to rigid with the use of LS-Dyna control card *DEFORMABLE_TO_RIGID_AUTOMATIC, during the body section free fall. During switching of the material properties, the time step was increased up to the value $2 \mathrm{e}-5 \mathrm{~s}$, whereas during the impact between the section and the ground surface and subsequent section's deformation, the time step was equal to $1 \mathrm{e}-6$ s. It should be noted that the value of the gravitational acceleration was intentionally reduced to 0 , on the calculation time interval from $t=2 \mathrm{~s}$ to $t=2.2 \mathrm{~s}$. It allows us to measure the residual deformation of the model.

All structural members of the body section were presented by shell elements in the FEM. The average model finite element size was $10 \mathrm{~mm}$. At assumed locations of plastic hinges emergences, the element size was $6 \mathrm{~mm}$, while at the tilting platform shoulders, the element size was $2.5 \mathrm{~mm}$ for ensuring of the contact interaction accuracy between the shoulders and body section pedestal. Total shell element number was equal to 230,567 . All nodes of the section's model interact with rigid ditch surface by LS-Dyna contact type *CONTACT_NODES_TO_SURFACE. The LS-Dyna contact type *CONTACT_SINGLE_SURFACE was assigned to the box with ballast and the body section's vertical pillars. The composed model view is shown in Fig. 5a.

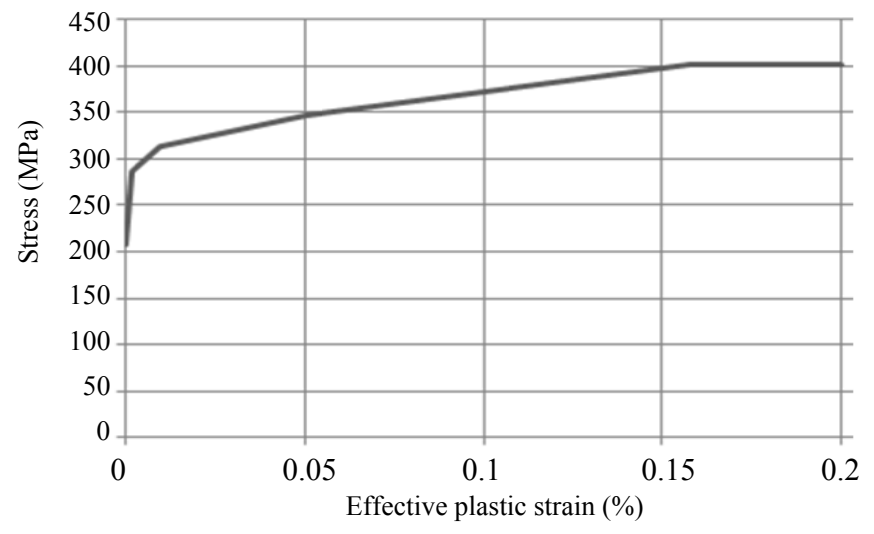

Fig. 4 The plastic hardening curve of steel.

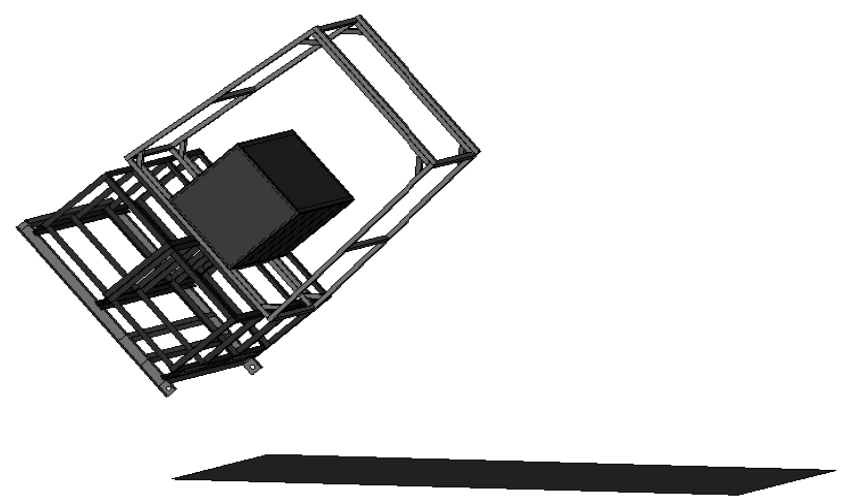

(a)

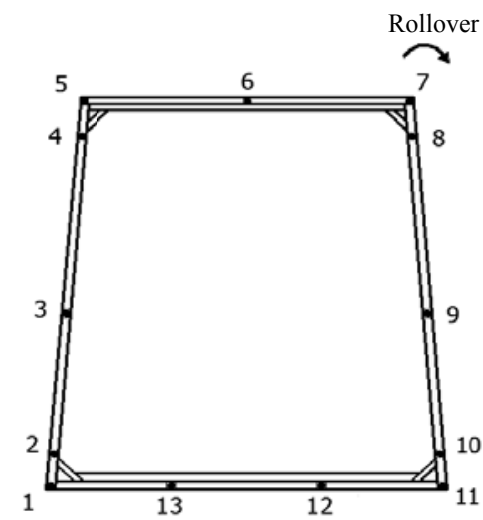

(b)

Fig. 5 Computer simulation and measurement: (a) the finite element model; (b) the control measured points location. 


\section{Comparison between Calculation and Experiment Data}

The distance between the control points before the impact and after was measured in the simulation and test. Comparison between the simulation and test results was conducted by the comparison between these distances. The residual deformations after unloading were measured after the impact. Location of the control points is shown in Fig. 5b. The measurements are shown in Table 1. As it is seen from the table, the difference between the simulation and test results has ranged from $0.36 \%$ to $7.29 \%$. Good correlation between the simulation and test results is also confirmed by comparison of the body section deformations as shown in Fig. 6.

It shows in Fig. 6 that the box with ballast touches the vertical pillars of the body section. This situation also takes place in calculation. It also shows that locations of the plastic deformations areas in calculation are the same as in the experiment.

\section{Analysis of the Bus Section Motion during Rollover}

Considering the obtained results, it is possible to say that the developed finite element model is adequate and correctly reproduces the movement of bus section before and after impact with ground. Several motion features of the bus section FEM will be shown further. The features can be considered as reliable, taking into account obtained convergence between experimental and calculation results.

Fig. 7 shows a graph of the model kinetic energy changing during the rollover process. In the graph, there are two sharp drops. The first $(t=1.69 \mathrm{~s})$ is caused by the fall of the section pedestal from the tilting platform. The intensive absorption of the kinetic energy at $t=1.81 \mathrm{~s}$ is caused by the contact of the lower parts of the structure with ground surface. A similar change of energy is described in details in Matolcsy and Molnar's study [8], which analyzed the energy balance of the bus rollover process. It should be noted that the impact between the lower parts of the structure and ground surface almost does not influence the deformation of the upper parts of the section. Sliding of the body section along the ground surface is the most obvious parameter which influences the fall of the pedestal (bus chassis) from the tilting platform shoulders.

The rotation axis of the bus body construction is changing during the rollover process. The tilting platform shoulders and the pedestal positions at different time moments are shown in Fig. 8. The rotation axis changing influences the inertia moment of the rotating construction and so influences the kinetic energy value. Also, the " $L$ " distance between the lower edge of the pedestal and rotation axis influences the fall of the pedestal from the tilting platform shoulders. Finally, it influences the bus body deformation values.

Table 1 The results of the experiment and computer simulation.

\begin{tabular}{|c|c|c|c|}
\hline \multirow{2}{*}{ Numbers of control points } & \multicolumn{2}{|c|}{ Change of the distance $(\mathrm{mm})$} & \multirow{2}{*}{ Difference between the results (\%) } \\
\hline & Test & Calculation & \\
\hline $1 \sim 7$ & 640 & 650 & 1.56 \\
\hline $1 \sim 8$ & 669 & 686 & 2.54 \\
\hline $2 \sim 6$ & 400 & 403 & 0.75 \\
\hline $3 \sim 13$ & -153 & -162 & 5.88 \\
\hline $4 \sim 12$ & -384 & -412 & 7.29 \\
\hline $5 \sim 11$ & -427 & -449 & 5.15 \\
\hline $4 \sim 11$ & -478 & -504 & 5.44 \\
\hline $6 \sim 10$ & -261 & -273 & 4.60 \\
\hline $9 \sim 12$ & 231 & 226 & 2.16 \\
\hline $8 \sim 13$ & 550 & 552 & 0.36 \\
\hline
\end{tabular}




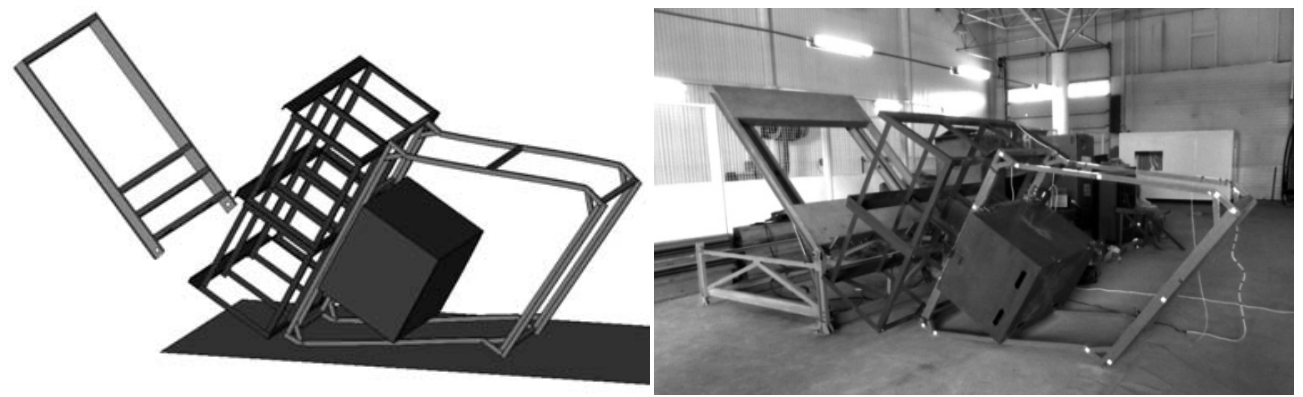

(a)

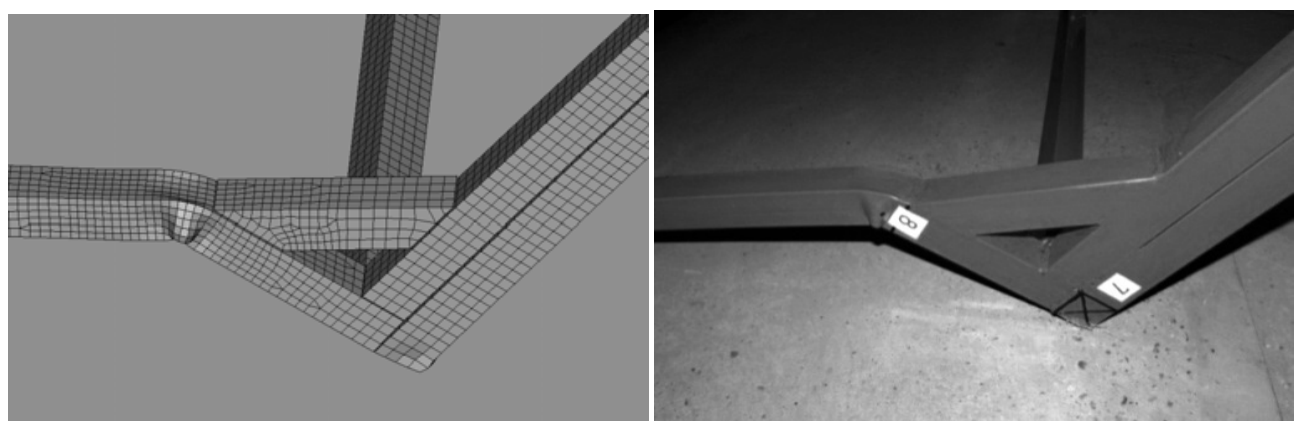

(b)

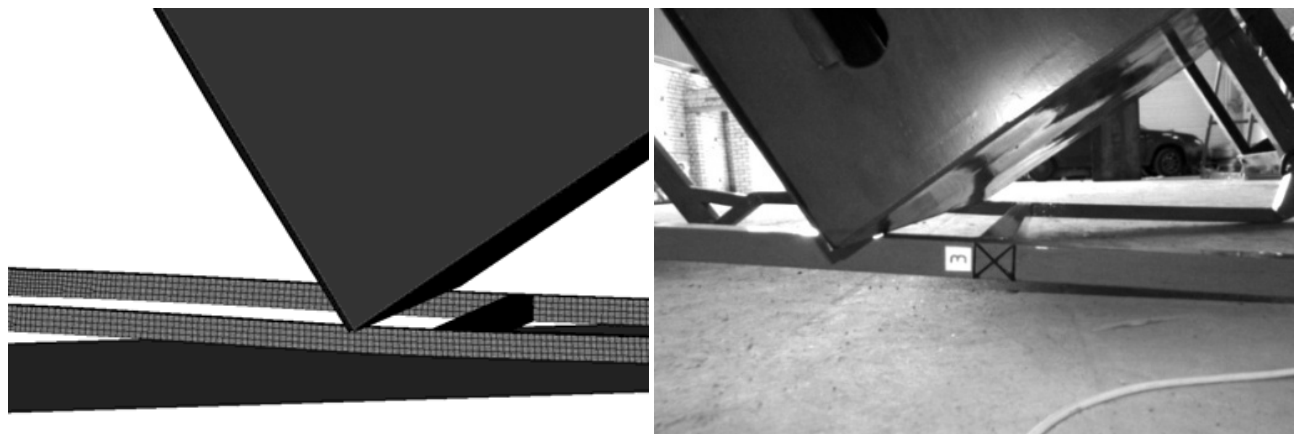

(c)

Fig. 6 Pictures of deformed conditions of the model and of the real body section construction: (a) the whole structure; (b) the upper corner of the roof; (c) contact between the box and vertical pillars.

Thus, taking into account the given features of rollover, experimental determination of the friction coefficient between the wheels of the bus (or a section pedestal) and rotating platform, as well as between the bus body and the ditch surface, is necessary to improve the accuracy of calculation. Good convergence between results of calculation and experiment was achieved in this paper using these methods. It should be understood that a numerical error for a large number of iterations, discretization of rounded contact surfaces and conditional stiffness of contact interaction given by the user take place in the nonlinear finite element analysis. There is necessity to verify the values of velocity and acceleration of model before impact with ditch surface. Thus, the experimental determination of the friction coefficient does not give the complete confidence in the correctness of the FEM movement.

Values of the velocity and acceleration of the section COG can be obtained without a full-scale experiment using an equations of rigid body motion. Mathematical model of planar motion of a rigid body was compiled and solved to the moment. This model consists of several systems of equations, which are solved sequentially when the variables reach appropriate conditions. Three settlement schemes that become relevant at certain stages of the bus planar motion during a rollover are shown in Figs. 9 and 10.

The system of equations compiled for the Scheme 2 


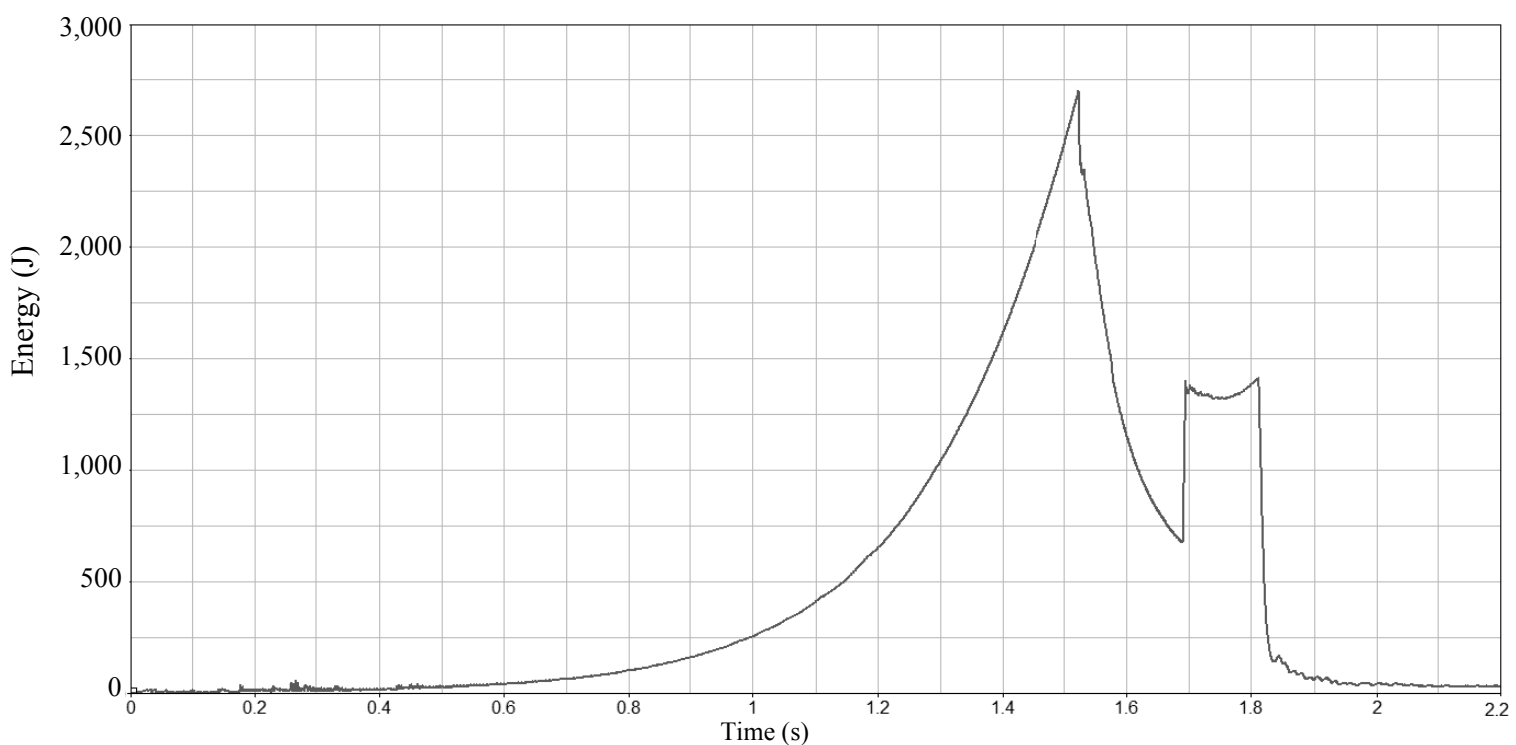

Fig. 7 Kinetic energy distribution versus time.

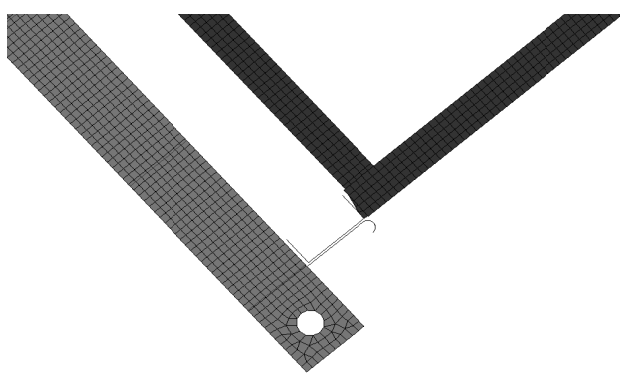

(a)

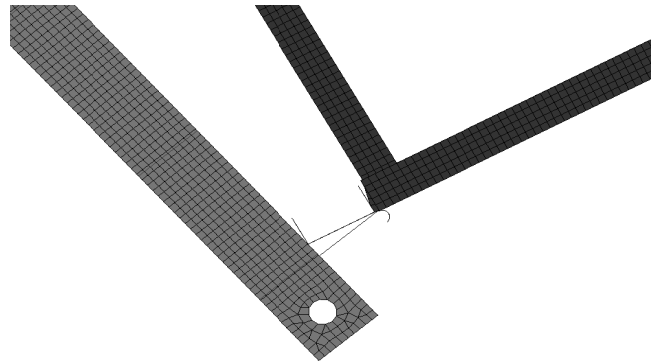

(b)

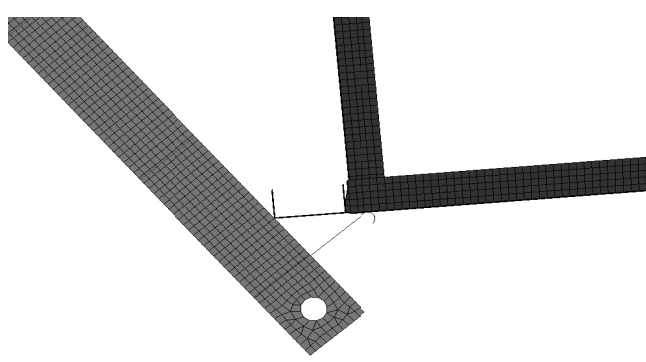

(c)

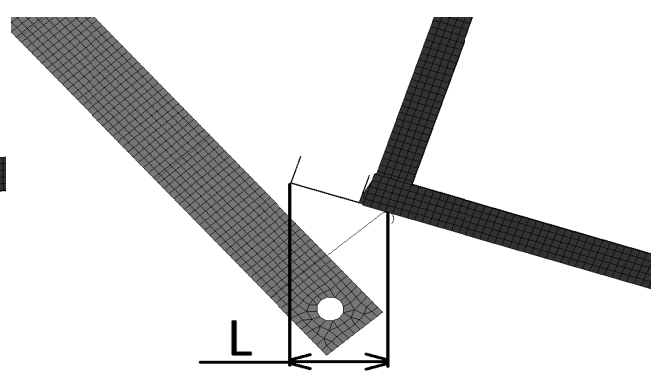

(d)

Fig. 8 The tilting platform shoulders and the pedestal positions at time: (a) $t=0 \mathrm{~s}$; (b) $t=0.9 \mathrm{~s} ;$ (c) $t=1.3 \mathrm{~s} ;$ (d) $t=1.5 \mathrm{~s}$.

(Fig. 9b) looks as follows:

$$
\begin{aligned}
& \left\{\begin{array}{c}
J \ddot{\varphi}=N_{1}\left(h_{c}-\frac{L_{2}}{\cos \left(\varphi_{1}-\varphi_{0}\right)}-\frac{2 \pi r\left(\varphi-\varphi_{0}\right)}{360}\right) \\
x=\sqrt{B^{2}+\left(h_{c}-\frac{L_{2}}{\cos \left(\varphi_{1}-\varphi_{0}\right)}-\frac{2 \pi r\left(\varphi-\varphi_{0}\right)}{360}\right)^{2}} \sin \left(\varphi-\varphi_{0}\right)(3)
\end{array}\right. \\
& m y=N_{1} \sin \varphi-m g+\mu N_{1} \cos \varphi \\
& y=\sqrt{B^{2}+\left(h_{c}-\frac{L_{2}}{\cos \left(\varphi_{1}-\varphi_{0}\right)}-\frac{2 \pi r\left(\varphi-\varphi_{0}\right)}{360}\right)^{2}} \cos \left(\varphi-\varphi_{0}\right)
\end{aligned}
$$

where, $J$ is inertia moment of the bus; $\ddot{\varphi}$ is angular acceleration; proportions $h_{c}, L_{2}$ and $B$ are shown in Fig. 9a; $x$ is horizontal displacement; $y$ is vertical displacement; $m$ is mass of the bus section; $\mu$ is friction coefficient; $r$ is vertex radius of the tilting platform shoulder; $N_{1}$ is reaction from tilting platform shoulders; $\varphi_{1}$ is angle at which the sliding is stopped; $\varphi_{0}$ is angle corresponding to the start of the bus rollover.

Equations for finding accelerations, obtained from the System 3 are presented below: 


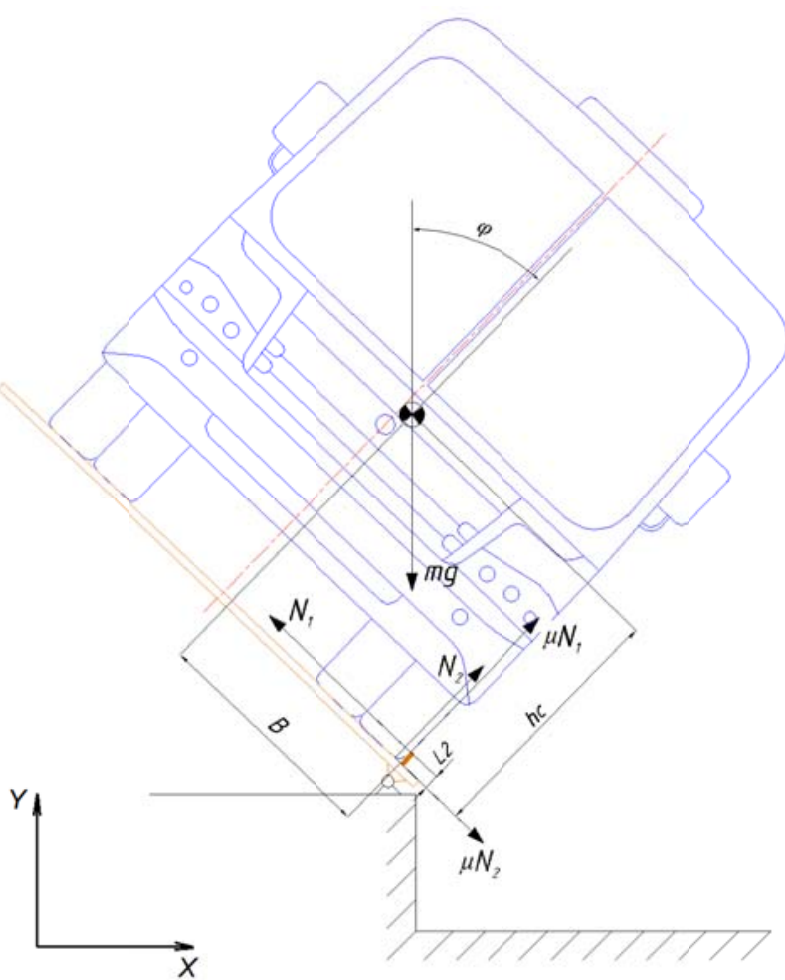

(a)

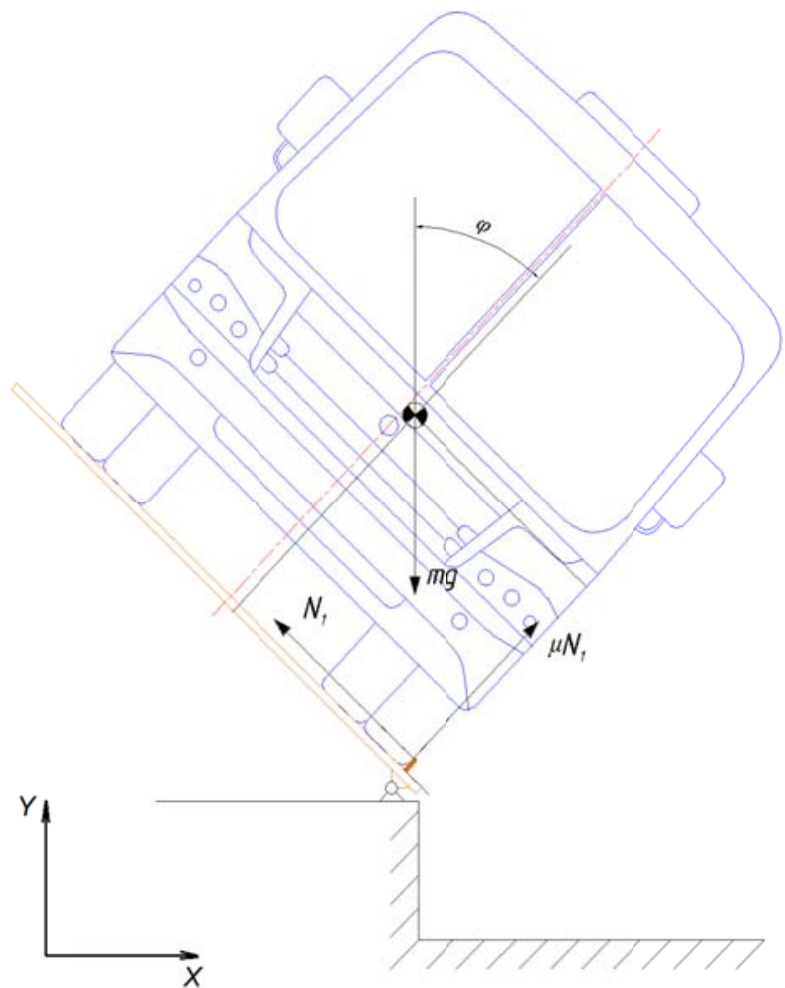

(b)

Fig. 9 Settlement schemes of bus motion when $\varphi<90^{\circ}$ : (a) Scheme 1 (taking into account a sliding between the construction and tilting platform shoulders); (b) Scheme 2 (without sliding).

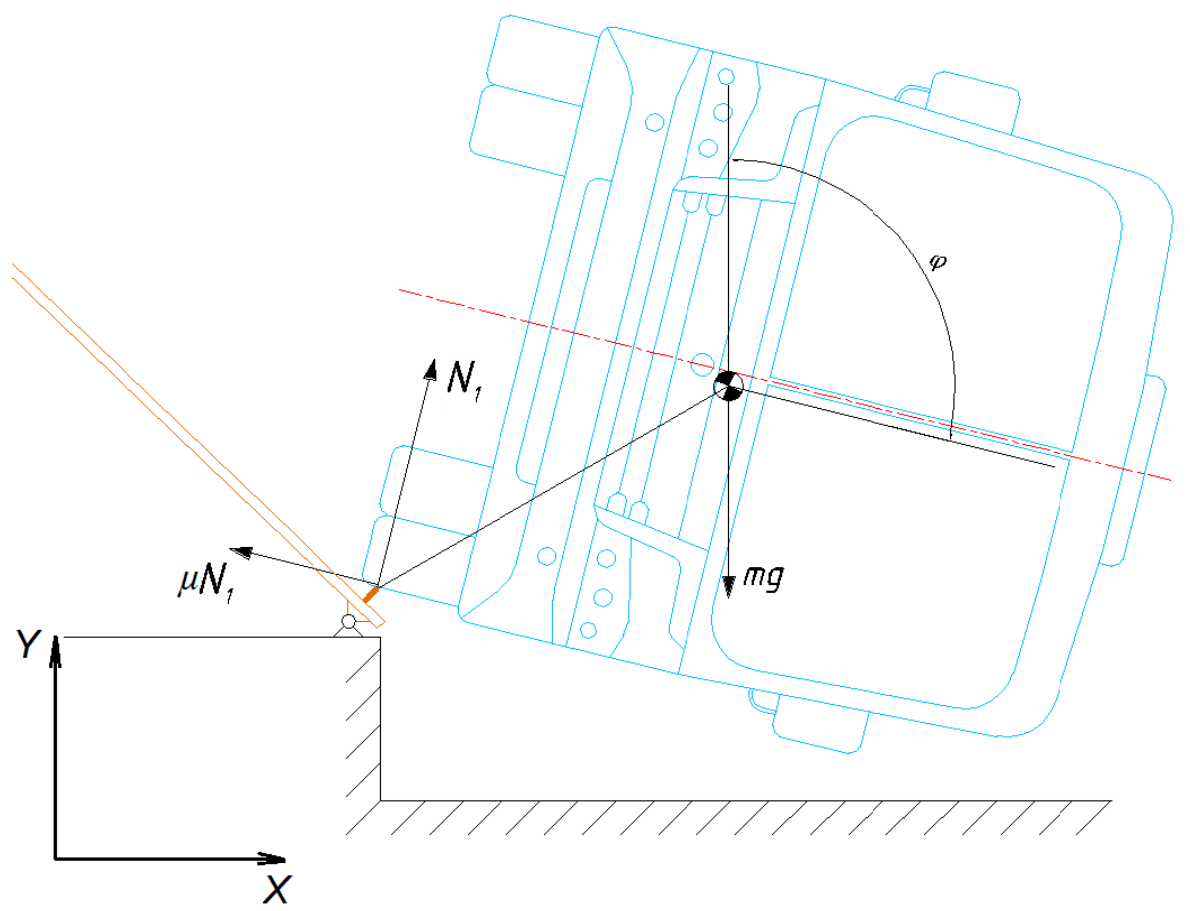

Fig. 10 Settlement scheme of bus motion when $\varphi \geq 90^{\circ}$. 


$$
\begin{aligned}
& \ddot{y}=-\frac{\cos \left(\varphi-\varphi_{0}\right)\left(h_{c}-\frac{L_{2}}{\cos \left(\varphi-\varphi_{0}\right)}\right)^{2}\left(-\frac{2 \pi r \dot{\varphi}}{360}\right)^{2}}{\sqrt{\left(B^{2}+\left(h_{c}-\frac{L_{2}}{\cos \left(\varphi-\varphi_{0}\right)}-\frac{2 \pi r\left(\varphi-\varphi_{0}\right)}{360}\right)^{2}\right)^{3}}}+\frac{2 \sin \left(\varphi-\varphi_{0}\right)\left(h_{c}-\frac{L_{2}}{\cos \left(\varphi-\varphi_{0}\right)}-\frac{2 \pi r\left(\varphi-\varphi_{0}\right)}{360}\right)\left(\frac{2 \pi r \dot{\varphi}^{2}}{360}\right)}{\sqrt{B^{2}+\left(h_{c}-\frac{L_{2}}{\cos \left(\varphi-\varphi_{0}\right)}-\frac{2 \pi r\left(\varphi-\varphi_{0}\right)}{360}\right)^{2}}} \\
& +\frac{\cos \left(\varphi-\varphi_{0}\right)\left(\frac{2 \pi r \dot{\varphi}^{2}}{360}\right)}{\sqrt{B^{2}+\left(h_{c}-\frac{L_{2}}{\cos \left(\varphi-\varphi_{0}\right)}-\frac{2 \pi r\left(\varphi-\varphi_{0}\right)}{360}\right)^{2}}}-\frac{\cos \left(\varphi-\varphi_{0}\right)\left(h_{c}-\frac{L_{2}}{\cos \left(\varphi-\varphi_{0}\right)}-\frac{2 \pi r\left(\varphi-\varphi_{0}\right)}{360}\right) \frac{2 \pi r \ddot{\varphi}}{360}}{\sqrt{B^{2}+\left(h_{c}-\frac{L_{2}}{\cos \left(\varphi-\varphi_{0}\right)}-\frac{2 \pi r\left(\varphi-\varphi_{0}\right)}{360}\right)^{2}}} \\
& -\sqrt{B^{2}+\left(h_{c}-\frac{L_{2}}{\cos \left(\varphi-\varphi_{0}\right)}-\frac{2 \pi r\left(\varphi-\varphi_{0}\right)}{360}\right)^{2}}\left(\cos \left(\varphi-\varphi_{0}\right) \dot{\varphi}^{2}+\sin \left(\varphi-\varphi_{0}\right) \ddot{\varphi}\right) \\
& \ddot{x}=-\frac{\sin \left(\varphi-\varphi_{0}\right)\left(h_{c}-\frac{L_{2}}{\cos \left(\varphi-\varphi_{0}\right)}-\frac{2 \pi r\left(\varphi-\varphi_{0}\right)}{360}\right)^{2}\left(\frac{2 \pi \dot{\varphi}}{360}\right)^{2}}{\sqrt{\left(B^{2}+\left(h_{c}-\frac{L_{2}}{\cos \left(\varphi-\varphi_{0}\right)}-\frac{2 \pi r\left(\varphi-\varphi_{0}\right)}{360}\right)^{2}\right)^{3}}}-\frac{2 \cos \left(\varphi-\varphi_{0}\right)\left(h_{c}-\frac{L_{2}}{\cos \left(\varphi-\varphi_{0}\right)}-\frac{2 \pi r\left(\varphi-\varphi_{0}\right)}{360}\right)\left(\frac{2 \pi \dot{y} \dot{\varphi}^{2}}{360}\right)}{\sqrt{B^{2}+\left(h_{c}-\frac{L_{2}}{\cos \left(\varphi-\varphi_{0}\right)}-\frac{2 \pi r\left(\varphi-\varphi_{0}\right)}{360}\right)^{2}}} \\
& +\frac{\sin \left(\varphi-\varphi_{0}\right)\left(\frac{2 \pi \dot{\varphi} \dot{\varphi}}{360}\right)^{2}}{\sqrt{B^{2}+\left(h_{c}-\frac{L_{2}}{\cos \left(\varphi-\varphi_{0}\right)}-\frac{2 \pi r\left(\varphi-\varphi_{0}\right)}{360}\right)^{2}}}-\frac{\sin \left(\varphi-\varphi_{0}\right)\left(h_{c}-\frac{L_{2}}{\cos \left(\varphi-\varphi_{0}\right)}-\frac{2 \pi r\left(\varphi-\varphi_{0}\right)}{360}\right) \frac{2 \pi \ddot{\varphi}}{360}}{\sqrt{B^{2}+\left(h_{c}-\frac{L_{2}}{\cos \left(\varphi-\varphi_{0}\right)}-\frac{2 \pi r\left(\varphi-\varphi_{0}\right)}{360}\right)^{2}}} \\
& -\sqrt{B^{2}+\left(h_{c}-\frac{L_{2}}{\cos \left(\varphi-\varphi_{0}\right)}-\frac{2 \pi r\left(\varphi-\varphi_{0}\right)}{360}\right)^{2}}\left(\sin \left(\varphi-\varphi_{0}\right) \dot{\varphi}^{2}-\cos \left(\varphi-\varphi_{0}\right) \ddot{\varphi}\right)
\end{aligned}
$$

Currently, the results obtained by mathematical simulation have not been compared with the experiment and are not shown in this article. Conduction of the verification of the developed mathematical model and development of a bus free movement mathematical model are planned in the nearest future.

\section{Conclusions}

Based on the analysis, we can formulate the following conclusions:

- The kinetic energy value of bus section impact depends on the friction coefficient between the tested structure and the tilting platform;

- The accuracy of the FEA can be improved by the experimental determination of the friction coefficient between the wheels of the bus (or a section pedestal) and tilting platform, as well as between the bus body and the ditch surface;

- Verification of velocities and accelerations of the bus section COG, obtained by FE simulation, can be conducted using the mathematical model of rigid body plane motion.

\section{Acknowledgments}

This research is performed with financial support of the Ministry of Education and Science of the Russian Federation within the framework of the project under contract No. 02.G25.31.0006 from December 2, 2013 (Resolution of the Government of the Russian 
Federation on April 9, 2010, No. 218).

\section{References}

[1] UNECE. 2006. Uniform Technical Prescriptions Concerning the Approval of Large Passenger Vehicles with Regard to the Strength of Their Superstructure, Rev. 1. Switzerland: UNECE.

[2] Guler, M. A., Atahan, A. O., and Bayram, B. 2011. "Crashworthiness Evaluation of an Intercity Coach against Rollover Accidents." International Journal of Heavy Vehicle Systems 18: 64-82.

[3] Bojanowski, C., Kwasniewski, L., and Wekezer, J. W. 2013. "Comprehensive Rollover Testing of Paratransit Buses." International Journal of Heavy Vehicle Systems 20: 76-98.

[4] Vashurin, A. S. 2014. Razrabotka Metodiki i Otsenki Passivnoy Bezopastnosti Kuzovov iz Mnogosloynyh Paneley Avtobusov (Development of Methods and
Assessment of Passive Safety of Shift Bus Bodies Made from Sandwich Panels). Nizhny Novgorod: NNSTU (Nizhny Novgorod State Technical University n.a. R. E. Alekseev). (in Russian)

[5] LSTC (Livermore Software Technology Corporation). 2011. Total Energy. California: Livermore Software Technology Corporation. Accessed June 15, 2014. http://www.dynasupport.com/howtos/general/total-energy.

[6] Castejon, L., Miravete, A., and Larrode, E. 2001. "Intercity Bus Rollover Simulation." International Journal of Vehicle Design 26 (2/3): 204-17.

[7] Belingardi, G., Gastaldin, D., Martella, P., and Peroni, L. 2003. "Multibody Analysis of M3 Bus Rollover: Structural Behaviour and Passenger Injury Risk." Presented at 18th International Technical Conference on the Enhanced Safety of Vehicles, Nagoya, Japan.

[8] Matolcsy, M., and Molnar, C. 1999. "Bus Rollover Test As a Process and Its Energy Balance." In Proceedings of 30th Meeting of Bus and Coach Experts, 167-74. 